\title{
KONTRIBUSI KEGIATAN EKSTRAKURIKULER KARATE DALAM PEMBENTUKAN KARAKTER DSIPLIN DAN TANGGUNG JAWAB PESERTA DIDIK DI MADRASAH IBTIDAIYAH
}

\author{
Hesti Nurul Isnaeni \\ IAIN Purwokerto \\ email: Isnaenihesty@gmail.com
}

\begin{abstract}
This study aims to observe the contribution of karate extrauricular activities to building the character of discipline and responsibility of students in MI Darul Hikmah Bantarsoka, West Purwokerto District, Banyumas Regency. This research is a field research, with a type of qualitative research. Data collection techniques use observation, interviews, and documentation. The data obtained from the three data collection techniques are then collected through triangulation of techniques and sources. From the results of the analysis conducted by researchers, karate extracurricular activities has positive contribution to building the character of discipline and responsibility in MI Darul Hikmah Bantarsoka, West Purwokerto District, Banyumas Regency. Students who take part in karate extracurricular activities have the character of discipline and responsibility. The disciplinary attitude of students can be seen through several activities such as: religious discipline, time discipline, discipline towards regulations, discipline of learning, and discipline in attitude. The character of the responsibilities of the students includes the responsibility of being exposed to the densiri, family, community, nation and state and God Almighty.
\end{abstract}

Keywords: Karate extracurricular activity, Discipline Character and Responsibility.

\begin{abstract}
ABSTRAK
Penelitian ini bertujuan untuk mengetahui kontribusi kegiatan ekstraurikuler karate dalam membentuk karakter disiplin dan tanggung jawab peserta didik di MI Darul Hikmah Bantarsoka Kecamatan Purwokerto Barat Kabupaten Banyumas. Penelitian ini merupakan penelitian lapangan atau field research, dengan jenis penelitian kualitatif. Teknik pengumpulan data menggunakan observasi, wawancara, dan dokumentasi. Data-data yang diperoleh dari ketiga teknik pengumpulan data tersebut kemudian dikumpulkan melalui triangulasi teknik dan sumber. Dari hasil analisis yang dilakukan oleh peneliti, kegiatan ekstrakurikuler karate memberikan kontribusi positif terhadap pembentukan karakter disiplin dan tanggung jawab di MI Darul Hikmah Bantarsoka Kecamatan Purwokerto Barat Kabupaten Banyumas. Peserta didik yang mengikuti kegiatan ekstrakurikuler karate mempunyai karakter disiplin dan tanggung jawab.
\end{abstract}


Sikap kedisiplinan peserta didik dapat kita lihat melalui beberapa kegiatan seperti: disiplin beribadah, disiplin waktu, disiplin terhadap peraturan, disiplin belajar, dan disiplin dalam bersikap. Adapun karakter tanggung jawab yang dimiliki peserta didik meliputi tanggung jawab terhaddap diri densiri, keluarga, masyarakat, bangsa dan negara serta Tuhan yang Maha Esa.

Kata Kunci: Kegiatan Ektrakurikuler Karate, Karakter Disiplin dan Tanggng Jawab.

\section{Pendahuluan}

Pendidikan formal pada dasarnya merupakan perluasan dari pendidikan keluarga. Pendidikan dalam konteks ini merupakan proses sosialisasi secara berkelanjuan dengan tujuan mengantarkan peserta didik agar menjadi manusia yang berkarakter baik. Banyaknya permasalahan dalam dunia pendidikan belakangan ini menunjukan kemerosotan moral yang cukup parah terhadap bangsa ini. Berbagai perilaku menyimpang seperti merokok, tawuran, seks bebas, tindakan kekerasan terhadap pendidik, dan lain sebagainya.

Banyaknya permasalahan pendidikan seperti yang telah disebutkan, disebabkan oleh beberapa faktor baik faktor eksternal maupun faktor internal. Salah satu faktor ekternal penyebab hal tersebut adalah karena pelaku pendidikan hanya fokus pada sisi intelektual saja, namun disisi lain justru mereka mengabaikan nilai-nilai moral yang harus dimiliki oleh peserta didik. Bukan hanya itu penyebab terjadinya permasalahan dalam dunia pendidikan khususnya kemerosotan moral bangsa antara lain: pendidik kurang tegas dalam menegur peserta didik, kurang adanya pemanfaatan waktu pada jam pelajaran yang kosong, kurangnya kegiatan yang menyenangkan sehingga peserta didik kurang senang dan menikmati waktu belajar mereka, pembinaan moral peserta didik sangat kurang baik dalam lingkungan keluarga, sekolah ataupun lingkungan masyarakat. ${ }^{1}$ Sedangkan faktor internal yang menyebabkan hal tersebut terjadi yaitu berkurangnya karakter disiplin dan tanggung jawab dalam diri peserta didik.

Landasan paling ideal dalam pembentukan karakter setiap individu adalah nilai-nilai iman dan takwa. ${ }^{2}$ Jika anak-anak tumbuh dan berkembang dengan berlandasan iman kepada Allah dan terdidik untuk selalu takut, ingat dan memohn perolongan Allah maka ia akan mempunyai kemampuan dan bekal untuk kehidupan di masyarakat serta terbiasa 
berakhakul mulia. Dengan demikian diharapkan peserta didik mampu mengembangkan kepribadian dan memiliki karakter tangguh, mandiri, disiplin, memahami hak dan kewajiban, tanggung jawab, dan kuat dalam menghadapi tantangan zaman. ${ }^{3}$ Dalam lingkup sekolah pendidik harus mampu menciptakan suatu kegiatan yang didalamnya terdapat nilai-nilai moral guna membentuk karakter peserta didik salah satunya yaitu kegiatan ekstrakurikuler, salah satunya yaitu ektrakurikuler beladiri karate.

MI Darul Hikmah Bantarsoka merupakan salah satu lembaga pendidikan yang melaksanakan program pendidikan karakter, salah satunya melalui kegiatan ekstrakurikuler karate. Karate merupakan salah satu cabang olahraga bela diri yang sudah sangat terkenal di berbagai Kalangan. Seiring perkembangan zaman karate semakin populer dan banyak digemari anak-anak dan remaja.

Karate merupakan jenis olahraga yang tegas tidak heran jika didalamnya terdapat nilai-nilai filosofi yang patut kita cermati bersama, seperti tatakrama dan budi pekerti luhur. Hal ini juga disebutkan dalam sumpah karate Indonesia, yaitu: sanggup memelihaa kepribadian (jinkaku kansei ni sutomoru koto), sanggup patuh pada kejujuran (matako no michi p mamoru koto), sanggup mempertinggi prestasi (reigi o omonzuru koto), sanggup menjaga sopa santun (doryokuo seishin o yoshiau koto), sanggup menguasai diri (keki no yu o iashimuru koto. ${ }^{4}$

Penelitian ini bertujuan untuk mengetahui kontibusi kegiatan ekstrakurikuler karate dalam pembentukan karakte disiplin dan tanggung jawab peserta didik di MI Darul Hikmah Bantarsoka Kecamatan Purwokerto Barat. Penelitian ini diharapkan dapat memberikan informasi terhadap masalah mengenai pembentukan karakter disiplin dan tanggung jawab kususnya melalui kegiatan ekstrakurikuler karate yang diselenggarakan di MI Darul Hikmah Bantarsoka Kecamatan Purwokerto Barat.

\section{Kegiatan Ekstrakurikuler Karate}

Kegatan ekstrakurikuler karate merupakan kegiatan yang bertujuan untuk mengembangkan bakat dan minat peserta didik daa bidang beladiri. Selain mengajarkan beladiri menggunakan tangan kosong ekstrakurikuler karate juga melatih peserta didik untuk memiliki karakter disiplin dan tanggung jawab. Kedisiplinan dan tanggung jawab ini dapat dibentuk melalui berbagai kegiatan karate baik latihan fisik, etika maupun nilainilai filosofis yang ada alam beladiri karate. 
Karate berasal dari negeri China. Karate diciptakan oleh Darma, Guru Budha Agung yang berakar di Okinawa melalui kontaknya dengan Cina pada petengahan abad ke-14. Pada abad ini, pengadilan Bakhcu di Oinawa membuat larangan menggunakan senjata. Dalam budaya Cina, kemp berasal dari kata "kara" yang berarti Cina dan "te"yang berarti tangan. Pada proses perkembangan selanjutnya, karate di Jepang idasarkan pada istilah "kara" yang berarti kosong dan"te" yang berarti tangan.

Pada hakikatnya, seni beladiri karate merupakan beladiri yang mengandalkan tangan kosong. Lahirnya karate sebagai seni beladiri di ketahui pada abad ke-19. Orang yang merjasa melajrkan beladiri karate dalah Matsumaa hukon, seorang prajurit amuarai dan pelidung Raja Soko Okinawa. Ia menciptakan karate dengan menggunakan unur seni militer Jepang (bushido). ${ }^{5}$

Rangkain kegiatan ekstrakurikuler karate meliputi: Berbaris dengan rapih, mengucapkan salam karate, mengucapkan sumpah karate, berdoa, pemanasan, kegiatan latihan inti, pendinginan, berdoa, mengucapkan sumpah karate, dan ditutup dengan salam. Dalam rangkaian kegiatan terdapat nilai-nilai kedisiplinan dan tanggung jawab, seperti: Karateka harus menggunakan dogi, memakai sabuk sesuai dengan tingkatannya mulai dari warna putih sampai hitam. Selain itu karateka juga harus mengusai teknik yang telah dipelajari sebagai karateka.

Selain kegiatan tersebut, karateka juga harus latihan teknik-teknik beladiri karate secara rutin, yang meliputi: kihon, kata, kumite. Kihon merupakan teknik dasar nagi seorang karateka. Kata merupakan bentuk atau pola suatu gerakan, oleh karena itu setiap kata mempunyai ritme dan ketentuan yang berbeda. Kata bukan sekedar latihan fisik namun didalamnya mengandung pelajaran tentang prinsip bertarung. Kumite merupaan pertemuan tangan atau pertandingan antar karateka tingkat lanjut.

\section{Pembentukan Karakter}

Istilah karakter berasal dari bahasa Yunani yang berarti to mark (menandai) dan memfokuskan, bagaimana seseorang mengaplikasikan nilai-nilai kebaikan dalam bentuk tindakan atau tingkah laku. ${ }^{6}$ Seseorang yang berperilaku baik seperti jujur, suka menolong, rajin maka dikatakan berkarakter baik atau karakter mulia, sedangkan seseorang yang bertindak buruk seperti berbohong, kejam, malas disebut dengan seseorang yang berkarakter buruk. Jadi istilah karakter sangat berhubungan erat dengan 
personality atau kepribadian seseorang, sehingga seseorang bisa disebut sebagai seseorang yang berkarakter apabila berperilku sesuai dengan kaidah normal.

Karakter juga dimaknai sebagai cara berfikir dan berperilaku yang khas tiap individu untuk hidup dan bekerja sama, baik dalam lingkup keluarga, masyarakat, bangsa dan negara. ${ }^{7}$ Secara psikologis karakter individu dimaknai sebagai hasil perpaduan dari empat bagian, yaitu: Olah hati, Olah pikir, Olah raga, Olah rasa dan karsa. Karakter seseorang berkembang berdasarkan potensi yang dibawa sejak lahir yang dikenal dengan karakter dasar yang bersifat biologis. ${ }^{8}$ Menurut Ki Hajar Dewantara, aktualisasi karakter dalam bentuk perilaku sehari sebagai yang merupakan bentuk perpaduan antara karakter dasar dan hasil interaksi dengan lingkungan sekitar. ${ }^{9}$

Thomas Lickona juga menjelaskan 3 poin yang sangat penting untuk mewujudkan karakter yang baik (components of good character), yaitu: Moral Knowing (moral pengetahuan), merupakan hal yang yang penting untuk di ajarkan. Moral felling (perasaan moral) merupakan sumber energi dari diri manusia untuk bertindak sesuai dengan prinsip-prinsip moral. Moral action (tindakan moral) adalah bagaimana membuat pengetahuan moral dapat diwujudkan menjadi tindakan nyata. Perbuatan tindakan moral ini merupakan hasil dari dua komponen karakter lainnya. ${ }^{10}$ Dari pemaparan diatas dapat dipahami bahwa pokok utama karakter ialah suatu tingkah laku dan pola pikir yang baik sesuai dengan nilai-nilai moralitas dan keberagamaan.

\section{Hakikat Disiplin}

Pengertian karakter disiplin sendiri jika dilihat secara etimologi, disiplin berasal dari bahasa latin discere yang berarti belajar. Dari kata ini kemudian muncul kata disciplina yang berarti pengajaran atau pelatihan. Seiring perkembangan waktu disiplin kemudian diartikan sebagai kepatuhan terhadap peraturan atau tunduk pada pengawasan dan pengendalian. ${ }^{11}$ Menurut Marzuki, disiplin merupakan sikap taat pada peraturan dan tata tertib yang berlaku baik itu di Sekolah, keluaraga ataupun lingkungan masyarakat. ${ }^{12}$ Sedangkan Longman Distionary of English and Culture menerjemahkan kata discciplina dalam empat makna, yaitu: metode pelatihan untuk menghasilkan ketaatan dan pengendalian diri, suatu keadaan teratur dan terkendali yang diperoleh dari hasil 
pelatihan, hukuman yang bertujuan untuk menghasilkan ketaatan, suatu cabang ilmu yang dipelajari dilembaga pendidikan. ${ }^{13}$

Disiplin merupakan sesuatu yang harus dikembngkan dalam diri guna membantu peserta didik mengembangkan kebaikan yang berupa rasa hormat, empati, dan mengontrol diri. Karakter disiplin merupakan salah satu hal yang paling penting dalam memahami karakter peserta didik. ${ }^{14}$ Dari penjelasan diatas dapat dipahami bahwa disiplin merupakan kemampuan diri untuk bersikap taat dan patuh terhadap norma yang berlaku di lingkungan sekitar

\section{Hakikat Tanggung Jawab}

Menurut Marzuki tanggun jawab adalah melaksanakan tugas secara sunggung-sungguh serta berani menanggung konsekuensi dari sikap perkataan dan perilakunya. ${ }^{15}$ Tanggung jawab dalam Kamus Lengkap Bahasa Indonesia berarti keadaan wajib menanggung segala sesuatunya (bila terjadi sesuatu boleh dituntut, dipersalahkan, diperkarakan, dan sebagainya). Tanggung jawab merupakan sikap dan perilaku seseorang untuk melaksanakan tugas dan kewajibannya yang seharusnya dilakukan terhadap diri sendiri, masyarakat, lingkungan (alam, sosial, dan budaya), Negara dan Tuhan Yang Maha Esa. ${ }^{16}$ Dari pemaparan diatas dapat dipahami bahwa tanggung jawab merupakan sikap tegas dan bersunggung-sungguh untuk melaksanakan kewajibannya baik terhadap diri sendiri, masyarakat, lingkungan, Negara dan Tuhan Yang Maha Esa.

\section{Metode Penelitian}

Penelitian ini merupakan penelitian deskriptif kualitatif. Penelitian ini bertujuan untuk mengetahui kontribusi kegiatan ekstraurikuler karate dalam membentuk karakter disiplin dan tanggung jawab peserta didik di MI Darul Hikmah Bantarsoka Kecamatan Purwokerto Barat Kabupaten Banyumas. Subyek penelitian adalah peserta ekstrakurikuler karate di MI Darul Hikmah Bantarsoka dari kelas 3 sampai kelas 5.

Teknik pengumpulan data yang diguanakan yaitu: Pertama, Observasi partisipan yaitu peneliti ikut terlibat dalam kegiatan yang diteliti. Teknik ini digunakan dengan cara pengamatan langsung kemudian mencacat perilaku atau kejadian secara sistematis terhadap fenomena yang sebenarnya. Melalui teknik ini, peneliti melihat secara langsung bagaimana kontribusi 
kegiatan ekstrakurikuler katate dalam pembentukan karakter disiplin dan tanggung jawab peserta didik di MI Darul Hikmah Bantarsoka.

Kedua, Interview atau wawancara. Wawancara tersebut berisikan pertanyaan terkait dengan kontribusi kegiaan ekstrakurikuler katate dalam pembentukan karakter disiplin dan tanggung jawab peserta didik di MI Darul Hikmah Bantarsoka Kecamatan Purwokerto Barat. Wawancara tersebut dilakukan kepada Kepala Madrasah dan Guru Pendamping Ekstrakurikuler Karate. Ketiga, Dokumentasi. Teknik ini digunakan untuk memperoleh data tentang kurikulum ekstrakurikuler karate, jumlah peserta dan dokumentasi kegiatan ekstrakurikuler karate di MI Darul Hikmah Bantersoka.

Dari data yang diperoleh, maka dilakukan analisis data dengan menggunakan analisi model Miles dan Huberman yang meliputi tiga langkah, yaitu: Pertama, Reduksi Data (Reduction Data) yaitu: merangkum, memilih hal pokok, memfokuskan pada hal yang pokok dan membuang hal yang tidak penting. ${ }^{17}$ Kedua, Penyajian Data (Data Display, yaitu: menyajikan data dalam bentuk naratif. Ketiga, Verifkasi Data /Conclusing Drawing, yaitu menarik kesimpulan terhadap data yang telah diperoleh dilapangan, yang kemudian didisplay dalam bentuk teks naratif.

Langkah terakhir setelah analisis data yaitu uji Keabsahan data dengan teknik triangulasi data yang diartikan sebagai pengecekan data dari berbagai sumber, cara dan waktu. ${ }^{18}$ Teknik triangulasi yang digunakan terhadap data yang berkaitan dengan kontribusi kegiatan ekstrakulikuler karate dalam pembentukan karakter disiplin dan tanggung jawab di MI Darul Hikmah Bantarsoka Kecamatan Purwokerto Barat Kabupateen Banyumas.

\section{Hasil Penelitian dan Pembahasan}

Pembentukan karakter disiplin dan taggung jawab peserta didik merupakan salah satu usaha yang dilakukan sekolah untuk membentuk karakter peserta didik agar mampu mengendalikan diri, bertanggung jawab dengan tugas-tugasya serta dapat berperilaku sesuai dengan nilainilai dan aturan-aturan yang ada.

Berdasarkan penelitian yang telah dilakukan, maka dapat kita kita lihat beberapa kegiatan yang berkontribusi dalam pembentukan karakter disiplin dan tanggung jawab dalam kegiatan ekstrakurikuler karate di MI Darul Hikmah Bantrasoka Kecamatan Purwokero Barat Kabupaten Banyumas: 


\section{Kegiatan Pembentuk Karakter Disiplin}

Berikut ini merupakan beberapa kegiatan yang berkontribusi dalam pembentukan karakter disiplin peserta didik:

a. Disiplin waktu

Waktu merupakan sesuatu yang sangat berharga, sehingga pendidik harus mampu memberikan pemahaman pada peserta didik betapa pentingnya menghargai dan memanfaatkan waktu, agar peserta didik mampu memanfaatkan waktu dengan baik sehingga muncul kedisiplinan dan rasa tanggung jawab dalam diri peserta didik. Seperti yang telah dijelaskan oleh bapak Heri Ules bahwa kegiatan ekstrakurikuler karate dimulai pada pukul 07.00 WIB, maka pada saat itu juga peserta didik harus sudah berada dilapangan untuk mengikuti kegiatan esktrakurikuler karate. Begitu pula ketika waktu kegiatan ekstrakurikuler telah habis yaitu pukul 08.05 WIB, maka siswa harus kembali ke madrasah untuk mengganti pakaian yang dipakai ketika latihan dengan seragam pada hari tersebut dan mengikuti kegiatan berikutnya. Selain tepat waktu dalam kegiatan ekstrakurikuler karate disiplin waktu juga nampak pada saat peserta didik masuk kelas tepat waktu baik saat pagi hari ataupun setelah jam istirahat selesai.

b. Disiplin berpakaian

Pakaian yang digunakan untuk latihan karate (dogi) merupakan salah satu faktor yang sangat penting dalam kegiatan esrakurikuler karate. Bapak Heri Ules menjelaskan bahwa setiap peserta didik yang mengikuti kegiatan ekstrakurikuler karate, harus berpakaian bersih dan rapih. Pakaian yang bersih dan rapih akan memberian kenyamanan bukan hanya untuk pemakainya tapi juga untuk setiap orang yang melihatnya.

Dengan menggunakan dogi yang bersih dan rapih maka peserta didik telah mencerminkan diri sebagai karateka yang disiplin dalam berpakaian. Dalam ekstrakurikuler karate juga diajarkan agar pesrta didik mengamalkan butir sumpah karate Jinkaku Kansei $\mathrm{Ni}$ sutomoru Koto (Sanggup Memelihara Kepribadian) salah satunya adalah berpakaian bersih dan rapih baik saat latihan ataupun dalam kehidupan sehari-hari.

Kebiasaan disiplin dalam berpakaian bukan hanya nampak ketika kegiatan ekstrakurikuler karate namun juga ketika kegiatan diluar sekolah seperti ketika pembelajaran dikelas maupun diluar kelas. 


\section{c. Disiplin berbaris}

Berbaris merupakan salah satu wujud latihan fisik. Berbaris diperlukan guna melatih peserta didik agar lebih disiplin. Dalam berbaris karateka berbaris sesuai dengan sabuk yang dia pakai. Warna sabuk dalam karate menunjukan posisi tingkatan yang dia miliki.

Melalui pembiasaan disiplin berbaris yang dilakukan ketika kegiatan ekstrakurikuler karate di MI Darul Hikmah Bantarsoka, karakter disiplin ini dapat diimplementasikan juga dalam kegiatan lain. Kedisiplinan saat berbaris bukan hanya nampak ketika kegiatan ekstrakurikuler karate namun mereka juga displin dalam hal lain seperti ketika antre berwudlu, disiplin dan rapih ketika sholat berjama'ah.

2. Kegiatan Pembentuk Karakter Tanggung Jawab

Berikut ini merupakan beberapa kegiatan yang berkontribusi dalam pembentukan karakter tangung jawab peserta didik:

a. Mengucapkan salam karate

Kegiatan mengucapkan salam karate, merupakan salam yang disampaikan kepada sesama karateka, senpei, dan dojo ketika sebelum dan setelah selesai kegiatan latihan. Hal ini merupakan salah satu bentuk sopan santun seorang karateka. Pengucapan salam karate merupakan salah satu wujud tanggung jawab peserta didik kepada diri sendiri, masyarakat, bangsa dan negara serta Tuhan Yang Maha Esa, yang mana pengucapan salam ini merupakan cerminan dari salah satu sumpah karate yang berbunyi sanggup mejaga sopa santun (doryokuo seishin o yoshiau koto).

MI Darul Hikmah merupakan salah satu lembaga pendidikan yang menetapkan peraturan untuk selalu menjaga sopan santun dan bergul di lingkungan sekitar khusunya di lingkungan sekolah baik kepada adik kelas, teman sebaya, kaka kelas, guru dan juga orang tua. Melalui pembiasaan mengucapkan salam dalam kegiatan karate ini memberikan kesan dalam diri peserta didik sehingga dalam kehidupan sehari-hari mereka terbiasa untuk mengucapkan salam dan menjaga sopan santun.

b. Berdoa dan mengucapkan sumpah karate

Kegiatan berdo'a dan mengucapkan sumpah karate saat memulai dan mengakhiri kegiatan ekstrakurikuler karate dilakukan oleh semua karateka secara bersama-sama dan dipimpin oleh salah satu 
karateka yang dipilih oleh senpei secara bergiliran dalam setiap pertemuan.

MI Darul hikmah menerapkan peraturan untuk berdo'an dan asma'ul husna setiap pagi ketika hendak memulai pelajaran, serta berdoa ketik hendak pulang yaitu ketika menutup pembelajaran. Hal ini merupakan salah satu implementasi pembiasaan yang dilalukakan setiap kegiatan ekstrakurikuler yaitu berdo'a dan mengucapkan sumpah karate. Adapun bunyi sumpah karate yaitu: sanggup memelihaa kepribadian (jinkaku kansei ni sutomoru koto), sanggup patuh pada kejujuran (matako no michi $p$ mamoru koto), sanggup mempertinggi prestasi (reigi o omonzuru koto), sanggup menjaga sopa santun (doryokuo seishin o yoshiau koto), sanggup mengguasai diri (keki no yu o iashimuru koto)

Dari sumpah ini kemudian tertanam karakter tanggung jawab karateka atas sumpah yang mereka ucapkan ketika memulai dan mengakhiri kegiatan. Indikator yang nampak antara lain: karateka mampu mengusai teknik yang diajarkan, menjalankan kewajibannya sebagai peserta didik seperti piket harian, mengerjakan PR dan lainlain.

c. Latihan keterampilan dasar karate

Kegiatan latihan keterampilan dasar karate merupakan kegiatan inti dari kegiatan ekstrakurikuler karate di MI Darul Hikmah. Kegiatan latihan keterampilan dasar karate merupakan salah satu bentuk pendidikan karakter tanggung jawab bagi pesertadidik. Melalui latihan keterampilan dasar ini peserta didik harus mampu menguasai teknikteknik yang diajarkan dan mengimplementasikannya, salah satu bentuk implementasi teknik karate yaitu ketika kumite (pertandingan). Dalam kumite karateka harus mampu mengimplementasikan teknik yang telah diajarkan agar dia mampu melindungi diri sendiri tanpa harus membahayakan lawannya.

MI Darul Hikmaah mendidik peserta didik untuk mempunyai karakter tanggung jawab, baik pada diri sendiri, orang tua, masyarakat, bangsa dan negara serta Tuhan Yang Maha Esa bukan hanya dalam kegiatan ekstrakurikuler karate. Bentuk tanggung jawab tersebut juga nampak dalam kegiatan lain di Sekolah yaitu mengusai materi yang telah diajarkan dan membuang sampah pada tempatnya. 


\section{Simpulan}

Berdasarkan hasil penelitian da pembahasan yang telah dilakukan oleh peneliti, maka dapat disimpulkan bahwa kegiatan ekstrakurikuler karate memberikan kontribusi positif terhadap pembentukan karakter disiplin dan tanggung jawab peserta didik di MI Darul Hikmah Bantarsoka Kecamatan Purwokerto Barat Kabupaten Banyumas. Sikap kedisiplinan peserta didik dapat kita lihat melalui beberapa kegiatan seperti: disiplin beribadah, disiplin waktu, disiplin terhadap peraturan, disiplin belajar, dan disiplin dalam bersikap. Adapun karakter tanggung jawab yang dimiliki peserta didik meliputi tanggung jawab terhaddap diri densiri, keluarga, masyarakat, bangsa dan negara serta Tuhan yang Maha Esa.

\section{Endnotes}

1 Tutuk Ningsih, Implementasi Pendidikan Karakter, (Purwokerto: Stain Press, 2015), hlm 9.

2 Abdullah Nashih 'Ulwan, Pendidikan Anak dalam Islam, (Jakarta: Pustaka Amani, 2007), hlm 193.

3 Rohinah M. Noor, The Hidden Curriculum: Membangun Karakter Melalui Kegiatan Ekstrakurikuler, (Yogyakarta: Insan Madani, 2012), 69).

4 Dewi Nastiti, Menjadi Karateka, (Jakarta: Be Campion, 2008) hlm 6.

5 Andro Mediawan, Ragam Ekskul Bikin Kamu Jadi Bintang, (Yogyakarta: Buku Biru, 2012), hlm116.

6 Marzuki, Pendidikan Karakter Islam. (Jakarta: Amzah, 2015), hlm 20.

7 Muchlas Samawi dan Hariyanto, Konsep dan Model Pendidikan Karaker, (Bandung: Remaja Rosdakarya, 2013), hlm 42.

8 Anwar Hafid dkk, Konsep Dasar Ilmu Pendidikan, (Bandung: Alfabeta, 2013), hlm 112.

9 Zubaedi, Konsep Dasar Ilmu Pendidikan, (Bandung: Alfabeta, 2011), hlm 14.

10 Mansur Muslich, Pendidikan Karakter: Menjawab Tantangan Krisis Multimensional, (Jakarta: Bumi Aksara, 2011), hal 134.

11 Ngainun Naim, Character Building (Optimalisasi Pendidikan dalam Pengembangan Ilmu dan Pembentukan Karaker Bangsa), (Yogyakarta: Ar-Ruzz Media, 2012), hal 143.

12 Marzuki, Pendidikan Karakter Islam..., hlm 99.

13 Ruswadi, Berdisiplin: Tidak Harus berseragam, (Bandung: Boenzeterprise. 2012), hlm 3.

14 Thomas Lickona, Character Matters (Persoalan Karakter), (Jakarta: Bumi Aksara, 2013), hal 175.

15 Marzuki, Pendidikan Karakter Islam..., hlm 98.

16 Hasbullah, Dasar-dasar Ilmu Pendidikan, (Depok: Rajawali Press, 2017), hlm 236.

17 Sugiyono, Metode Penelitian Pendidikan (Pendekatan Kualitatif, Kuantitatf, dan R\&D, (Bandung: Alfabeta, 2018, hlm 338.

18 Sugiyono, Metode Penelitian Pendidikan..., hlm 372). 


\section{DAFTAR PUSTAKA}

Hafid, Anwar dkk, 2013. Konsep Dasar Ilmu Pendidikan. Bandung: Alfabeta. Hasbullah. 2017. Dasar-dasar Ilmu Pendidikan. Depok: Rajawali Press.

Lickona, Thomas. 2013. Character Matters (Persoalan Karakter). Jakarta: Bumi Aksara.

Marzuki. 2015. Pendidikan Karakter Islam. Jakarta: Amzah.

Mediawan, Andro. 2012. Ragam Ekskul Bikin Kamu Jadi Bintang. Yogyakarta: Buku Biru.

Muslich, Mansur. 2011. Pendidikan Karakter: Menjawab Tantangan Krisis Multimensional. Jakarta: Bumi Aksara.

Naim, Ngainun. 2012. Character Building (Optimalisasi Pendidikan dalam Pengembangan Ilmu da Pembentukan Karaker Bangsa). Yogyakarta: Ar-Ruzz Media.

Nastiti, Dewi. 2008. Menjadi Karateka. Jakarta: Be Campion.

Ningsih, Tutuk. 2015. Implementasi Pendidikan Karakter. Purwokerto: Stain Press

Noor, Rohinah M. 2012. The Hidden Curriculum: Membangun Karakter Melalui Kegiatan Ekstrakurikuler. Yogyakarta: Insan Madani.

Ruswadi. 2012. Berdisiplin: Tidak Harus berseragam. Bandung: Boenzeterprise.

Samawi, Muchlas dan Hariyanto. 2013. Konsep dan Model Pendidikan Karaker. Bandung: Remaja Rosdakarya

Sugiyono. 2018. Metode Penelitian Pendidikan (Pendekatan Kualitatif, Kuantitatf, dan R\&D. Bandung: Alfabeta.

'Ulwan, Abdullah Nashih. 2007. Pendidikan Anak dalam Islam. Jakarta: Pustaka Amani.

Zubaedi, Desain Pendidikan Karakter. 2011. Jakarta: Kecana Prenada Media Group. 